\title{
Therapeutic Communication Strategies in Nursing Process of Angry, Anxious, and Fearful Schizophrenic Patients
}

\author{
Iskandarsyah Siregar ${ }^{1} \square$ Firlii Rahmadiyah $^{2}$, Alisha Firiska Qatrunnada Siregar ${ }^{3}$ \\ ${ }^{1}$ Universitas Nasional, Indonesia \\ ${ }^{123}$ Regaranggi Institute, Indonesia \\ $\square$ Corresponding Author: Iskandarsyah Siregar, E-mail: regaranggi@presidency.com
}

\section{ARTICLE INFORMATION}

Received: 08 October 2021

Accepted: 22 November 2021

Published: 28 December 2021

DOI: 10.32996/bjns.2021.1.1.3

\section{KEYWORDS}

The therapeutic communication, nursing process, Skizofrenia patients

\section{ABSTRACT}

Schizophrenia is a group of psychotic disorders with primary personality disorders, characteristic distortions of thought processes. Schizophrenic disorders are characterized by fundamental and characteristic distortions of thought and perception and incompatible or blunted effects. Anger, anxiety, and fear are the most common hallucinations in Schizophrenic patients. These feelings drive the continued negative behaviour of the Schizophrenic patient. The therapeutic communication technique in the nursing process is one of the techniques in the healing process of patients, especially those with mental disorders nursing problems. This study was conducted based on anxiety about the results of observations, preliminary research, and reports obtained about the number of therapy failures for Schizophrenic patients caused by communication errors during treatment. In this study, researchers aimed to determine the Therapeutic Communication of Nurses to Patients. This qualitative research uses a Quasy-experimental design using a One-Group Pre-Post Test Design research design. The conclusion emerged in the study that 22 people (88\%) of respondents were in the Bad category in controlling negative thoughts. Meanwhile, three respondents (12\%) have an excellent ability to control negative thoughts. There are also research results that show 3 variables that support effective and efficient therapeutic communication. These are Build Trust, Troubleshooting with Constructive Coping, and Giving Appreciation.

\section{Introduction}

Schizophrenia is a group of psychotic disorders with primary personality disorders, characteristic distortions of thought processes. Schizophrenic disorders are characterized by fundamental and characteristic distortions of thought and perception and incompatible or blunted effects.

Schizophrenia is a mental disorder problem with a small prevalence but is still a crucial problem in Indonesia because of the impact it causes. More than $80 \%$ of people with Schizophrenia in Indonesia are not treated and are not handled optimally by the family and the medical team. People with Schizophrenia are left on the streets. Their families even shackle some. Conditions like this allow an increase in the number of people with Schizophrenia from time to time (Susanto, 2009).

According to data from the World Health Organization (WHO), in 2016, there were 21 million people affected by Schizophrenia. An epidemiological study in 2010 stated that the estimated prevalence of Schizophrenia in Indonesia is $0.3-1$ percent and usually occurs at the age of 18-45 years, but there are also those aged 11-12 years who already suffer from Schizophrenia. If the total population of Indonesia is around 256,603,197 people, then the estimated number of people with 2,566,031 people is Schizophrenia. Based on the 2013 Basic Health Research (Riskesdas) results, the incidence of severe mental disorders with Schizophrenia is 1.7 per 1000 population or about 400,000 people. A report from Human Rights Watch (HRW) noted that 57,000 people were diagnosed with mental problems, and as many as 18,800 people in Indonesia were shackled and experienced neglect from their families (HRW, 2016).

Copyright: (c) 2021 the Author(s). This article is an open access article distributed under the terms and conditions of the Creative Commons Attribution (CC-BY) 4.0 license (https://creativecommons.org/licenses/by/4.0/). Published by Al-Kindi Centre for Research and Development, London, United Kingdom. 
One of the symptoms of psychosis experienced by people with mental disorders is hallucinations which are perceptual disturbances in which the client perceives something that is not happening (Stuart, 2013). Hallucinations are sensory perceptions of sight, touch, hearing, smell/taste without external stimuli. Treatment actions for clients with hallucinations are psychopharmaceutical treatment and electrical seizure therapy (Direja, 2011). Anger, anxiety, and fear are the most common hallucinations in Schizophrenic patients. These feelings drive the continued negative behaviour of the Schizophrenic patient. Nursing actions that can be given are modality therapy, including individual therapy, environmental therapy, cognitive therapy, behavioural therapy, group therapy, and family therapy through communication (Keliat \& Prawirowiyono, 2016).

People with Schizophrenia will experience cognitive, emotional, perceptual, and behavioural disturbances (Maryatun, 2013). Distortion of negative thoughts that appear in Schizophrenic clients can trigger mental stress, resulting in anxiety, depression, or even an urge to commit suicide. This is a consequence that must be avoided at all costs.

Nursing services are provided to clients primarily with hallucinations and anxiety, generally by providing psychopharmaceutical treatment and therapeutic nursing modalities (group activity therapy, recreational therapy, environmental therapy, individual therapy, and occupational therapy). Individual therapy is a form of therapy carried out individually by nurses to clients in a nurseclient face-to-face with a particular duration of time following the goals to be achieved (Yusuf et al., 2015). The implementation is by using therapeutic communication carried out by nurses with patients who have the goal to control hallucinations. With this therapeutic communication technique, it is helpful to build a therapeutic relationship between nurses and clients, identify client problems, examine client perceptions of the problems they face. The therapeutic communication technique is one of the techniques in the healing process of patients, especially those with mental disorders nursing problems, including mental disorders patients with hallucinations (Stuart, 2013).

In treating Schizophrenic patients, communication strategies are essential in achieving the patient's healing orientation target. Appropriate communication steps during the treatment process are the upstream success in the entire therapy process. Many experts believe that communication itself can be the sole therapy in the healing strategy of Schizophrenia patients.

New research is worth doing if it touches at least one of these two traits: urgent and interesting (Siregar et al., 2021, p. 51). This study was conducted to find and describe effective therapeutic communication strategies in the nursing process of Schizophrenic patients in overcoming their anxiety, anger, and fear. This study was conducted based on anxiety about the results of observations, preliminary research, and reports obtained about the number of therapy failures for Schizophrenic patients caused by communication errors during treatment.

The results of this study are expected to be a reference for the realization of a nursing communication model for Schizophrenic patients. Furthermore, this research can also be used as a reference for realizing strategies, tactics, and models of communication technology in treating patients with any disease.

\section{Research methods}

The research approach used in this study is qualitative. A qualitative approach is a research that explains the phenomenon in depth (Kriyantono, 2006, p. 56). This study prioritizes the size of the population or sampling even the population or sampling is minimal. If the data collected is deep and can explain the phenomenon under study, there is no need to look for another sampling. This research belongs to the type of descriptive research that aims to describe or describe the complex social realities in society (Taher, 2009, p. 14). In this study, researchers aimed to determine the Therapeutic Communication of Nurses to Patients.

This study uses a Quasy-experimental design using a One-Group Pre-Post Test Design research design. In this study, the subject group was observed before the intervention was carried out, then re-observed after the intervention. Analytical survey techniques are also used in this study to try to explore how and why health phenomena occur.

The next strategy to be applied is to analyze the dynamics of the correlation between phenomena or between risk factors and effect factors. This study also uses a cross-sectional approach which emphasizes the time of observing the data of the independent and dependent variables only once. In this study, the variables were the relationship between nurse communication patterns and strategies with the healthy development of schizophrenic patients.

Respondents in this study were clients who experienced Schizophrenia, with 25 respondents. This type of research is a Quasy Experimental research design with One Group Pre Test Post Test research design. In this study, schizophrenic clients were given an adapted treatment process in 5 sessions of various communication therapy and lasted for eight days. The first session was conducted on the first and second days. After that, the second was conducted on the third and fourth days. The third was conducted on the fifth day. The fourth session was conducted on the sixth day. Finally, the fifth session was conducted on the seventh and eighth days. Each session was held for \pm 75 minutes. 


\section{Literature Reviews}

Communication is an essential aspect that nurses must own in carrying out nursing care for clients. Communication applied by nurses to patients is therapeutic communication. In the nursing profession, communication becomes more meaningful because it is the primary method in implementing the nursing process. The experience of science to help others requires special abilities and great social care. For this reason, nurses need special abilities and social care that includes intellectual, technical, and interpersonal skills, which are reflected in affection and love behaviour (Abdul Nasir et al., 2009, p. 142).

Therapeutic communication is consciously planned communication, aims and activities centred on the patient's recovery (Setiawan \& Tanjung, 2001, p. 21). In this relationship, the client feels valued, accepted, and directed. Clients will voluntarily express their feelings and thoughts so that the emotional burden and tension they feel can disappear entirely and return to normal. Therapeutic communication views health problems are originating from communication disorders, in the patient's inability to express himself (Marhaeni, 2009:5). Therefore, the purpose of therapeutic communication is to help patients clarify and reduce the burden of feelings and thoughts, help take practical actions for patients, help influence others, the physical environment, and themselves. There are five stages of therapeutic communication: Pre-Interaction, introduction, orientation, work activities, and termination (Abdul Nasir et al., 2009, p. 170).

It is also necessary to describe the symptoms that appear in Schizophrenia patients so that the severity can be accurately measured to decide the intensity of treatment. According to Iskandar (2012), the symptoms that people with Schizophrenia can observe include:

\section{A. Delusional disorder}

Delusional disorder, also known as disorder of thought content or fundamental character of madness, is a symptom of a psychotic disorder in schizophrenic patients characterized by thought disturbances and strong beliefs that misrepresent their beliefs. Therefore, clients with Schizophrenia have strong beliefs about what they think and end up ignoring their own needs such as bathing, decorating, eating, defecating, or urinating.

B. Hallucinations

Hallucinations are symptoms of psychotic disorders in people with Schizophrenia, characterized by the impaired perception of various things that can be seen, heard, or felt humiliated even though they are not realistic. Clients pay too much attention to the perceptions they experience so that their needs are not met independently.

\section{Disorganized}

Disorganization is a psychotic disorder of people with Schizophrenia that is characterized by an inability to regulate the direction of speech, emotional reactions, and motor behaviour.

D. Affective flattening

Affective flattening is a symptom of a psychotic disorder in schizophrenic patients characterized by their inability to regulate inappropriate emotional reactions and unusual hoarding.

\section{E. Alogia}

Alogia is a symptom of a psychotic disorder of schizophrenic patients characterized by a deficiency characterized by the amount of content of speech. The clinical characteristics of alogia are that the answers given by the patient are short or short, tend to be less interested in speaking, more silent and inadequate communication, negative thoughts and communication disorders, difficulty in formulating words.

\section{F. Avolisi}

Avolition is a symptom of a psychotic disorder of schizophrenic patients characterized by the inability to maintain or maintain essential activities. The clinical characteristics of avolition disorder are not showing interest in activities or functions of daily life and not being interested in taking care of their body health, tend to be lazy and dirty. So it can be concluded that patients with Schizophrenia are very susceptible to self-care deficits.

\section{G. Anhedonia}

Anhedonia is a symptom of a psychotic disorder of schizophrenic patients, which is characterized by a lack of pleasure, an indifferent attitude towards daily activities, a tendency to dislike eating, and an indifference to social interactions or sex.

\section{Results and Discussions}

Based on field data during the study, a total of 22 people (88\%) of respondents were in the wrong category in controlling negative thoughts. Meanwhile, three respondents (12\%) have an excellent ability to control negative thoughts. All respondents who participated in this study were schizophrenic patients who were classified randomly for the record. Schizophrenic patients who 
have poor ability to control negative thoughts are at risk of experiencing anxiety, depression, or even suicide because of mental stress from feelings of anxiety, anger, and fear.

Most Schizophrenia patients who were respondents in this study revealed that sometimes when they have a problem that is a burden on their minds, they tend to want to tell their problems to family members. Nevertheless, on the other hand, they are afraid to tell their family members because they feel that when they tell their problems to their family members, their family members will be burdened with the problem. Thus, these respondents choose to keep their problems to themselves, and sometimes these problems are ultimately unable to be solved by them. This situation then gives the effect of "popping balloons" on the psychiatric system of Schizophrenic patients.

From the observations made, it was also found that from several respondents, several Schizophrenic clients had family group members or a core environment that tended to not care about the condition of their family members who had Schizophrenia. Even in some cases, it was found that there were family members of schizophrenic patients who often gave negative assessments of their family members who had Schizophrenia. This is the dominant factor that underlies this schizophrenic patient who cannot solve his problems related to anxiety, anger, and fear that often bother him. So that makes this Schizophrenia patient can control evil negative thoughts. Here, it can be concluded that the patient care strategy in interpersonal interaction is the first step in the healing process and treatment of Schizophrenic patients.

In the process of adapted treatment in the form of 5 sessions of various communication therapy and carried out for eight days, it is seen that the ability to control anxiety, anger and fear of Schizophrenic patients can improve well. In this implementation, family members play a more dominant role to become a support system for family members who have Schizophrenia. By the goals of this treatment, namely being able to monitor negative automatic thoughts, recognize the relationship between cognitive, affective, and behaviour, correct the causes of negative automatic thoughts, change the interpretation to a more realistic direction due to incorrect thinking, and learn to identify and change beliefs. Wrong as a result of a negative experience.

In implementing this adapted treatment process, each treatment respondent has different characteristics in undergoing therapy. Most of the respondents have an enthusiastic attitude in participating in every series of cognitive therapy processes, especially respondents who fall into late adolescence and early adulthood. Meanwhile, respondents who fall into late adulthood, early elderly, and late elderly tend to be slow in understanding the explanations given. Researchers must repeat each explanation to understand respondents better to understand and follow the therapy process properly. However, in general, respondents who participated in this therapy process could follow the cognitive therapy process well.

At the end of each meeting, the researcher always reminded the schizophrenic client to practice and filled out the therapy manual if he was thinking about disturbing negative things. In addition, researchers also remind accompanying family members always to help schizophrenic clients, either to remind them to practice or help schizophrenic clients solve any problems they think.

On average, in the therapy process, respondents still have negative thoughts that they think about in the first and second sessions, although respondents say that they continually practice at home. In the last session, namely the fifth session, the average respondent said that their anxiety, anger, and fear began to decrease in intensity. They also feel happy when they can control their negative thoughts. However, some respondents feel they have not succeeded and still think negatively even though they have practised according to the directions in the adapted treatment process.

When given treatment, negative thoughts that arise in Schizophrenia patients manifest in various forms. Some expressed their anxiety about the future of their overall health due to their Schizophrenia disease. Some spoke about family problems that made them feel they had no benefit. Some show a fear that their parents will abandon them, siblings, or anyone around them. Some of them express problems about him that he may not be able to get married because of the condition of those diagnosed with Schizophrenia.

In this adapted treatment process, in the fourth and fifth sessions, the average respondent revealed that they felt happy after receiving treatment in the form of various communication therapy. Some respondents have also started to open up with family members and have more motivation and encouragement to solve their problems. Families who participated in therapy also revealed that they felt a little helped by the process of adapted treatment given to their family members who became Schizophrenia patients. There is a further conclusion that the effect caused by the provision of this varied communication therapy can increase the ability to control anger, anxiety, and fear in Schizophrenic patients and also be able to increase motivation, pleasure, and openness in solving any problems that they always think.

However, during the research process, which lasted a short eight days, it was found that none of the respondents was able to eliminate their negative thoughts permanently. They only succeed in reducing the intensity of the emergence of their anger, anxiety, and fear. There is a further hypothesis that these negative thoughts in Schizophrenic patients can disappear if therapy lasts longer. 
There is also a side conclusion that there are differences in depression conditions after the implementation of cognitive therapy, which shows that the decrease in depression in the elderly group who received cognitive therapy (intervention group) was higher $(p$-value $=0.001<0.05)$ compared to the decrease in depression in the group who did not receive treatment adapted treatment process.

Based on the results of further analysis using the Wilcoxon test method, a value of 0.001 was obtained, thus based on this analysis, and it can be seen that $p<0.05$. This shows a significant effect of the adapted treatment process on the ability to control negative thoughts in Schizophrenic clients. After Cognitive Therapy was performed, 22 respondents (88\%) had good negative thought control skills, while three respondents (12\%) still had poor negative thought control skills. This is in line with several studies conducted by many previous researchers, which stated that cognitive therapy had a significant effect on the ability to control negative thoughts in hospitalized cancer clients. Many similar studies also show that cognitive therapy influences a person's level of depression, where depression conditions before and after giving cognitive therapy ( $p$-value $<0.05$ ).

This study also found results that show the inhibiting factor of therapeutic communication between nurses (from internal or external elements of the family) is the age development factor, where in order to communicate effectively with patients, nurses must understand the influence of age development both in terms of language and thought processes of that patient. In the context of care in mental hospitals, the age factor greatly influences therapeutic communication between nurses and Schizophrenic patients. In elderly Schizophrenic patients, the inhibiting factor is because most of these patients already have dementia and hearing loss.

Emotions are subjective feelings about an event. The way a person relates and communicates with others is influenced by his or her emotional state. Emotions such as sadness, anxiety, anger, and fear affect health workers in communicating with others. In Mental Hospital, the patient's emotions also affect the communication between nurses and Schizophrenic patients. If the patient is angry, anxious, or afraid, it will hinder communication and difficult to talk to anyone.

The research and observations made in this study indicate that there are factors that inhibit therapeutic communication. This is in line with the social penetration theory that the relationship between individuals has a very diverse nature in terms of their social penetration. They start from the relationship between husband and wife, superior-subordinate, doctor-patient, or relationships between friends. Based on the theory of social penetration, the therapeutic communication process carried out by nurses to patients has various characteristics according to their social penetration.

There are also research results that show 3 variables that support effective and efficient therapeutic communication. These are Build Trust, Troubleshooting with Constructive Coping, and Giving Appreciation.

A. Build Trust

Trust is needed to build effective communication between nurses and patients. This variable occurs in the implementation of therapeutic communication at each phase, orientation, work, and termination phases between nurses and people with a mental health condition. The trust built from the start creates a sense of comfort and creates a therapeutic environment. Building a trusting relationship will make the relationship smoother going forward because the patient and the nurse are more open about the problems they face. In building a trusting relationship, the patient will assess the nurse from the first meeting and since the start of the therapeutic communication process. A trusting relationship is also characterized by respecting patients by maintaining patient confidentiality. With frequent communication, the client's trust in the nurse will be even more significant so that the patient will openly tell the problems faced by the patient. Clients also feel open to listening to advice or suggestions and solutions given by nurses.

\section{B. Troubleshooting with Constructive Coping}

Problem-solving with constructive coping is problem-solving in a positive way. Nurses teach this to Schizophrenia patients to build client understanding of the problems they are facing and can solve these problems with positive things, not through negative things. The nurse must be able to find out or collect patient data first to identify patient problems and explore patient stressors, which in the end in the nurse's work phase can provide good suggestions or solutions. Motivate patients to recover quickly, train patients' abilities, and explore the patient understanding of what nurses have taught to Schizophrenia patients themselves. After collecting data about the client or identifying the client's problems, the nurse will explore the client's stressors or what makes him stressed so that he is in the hospital in a language that does not offend the patient. Nurses do problem-solving in the work phase. This is where nurses explore patient stressors. After the nurse knows what the patient's problem is, the nurse will provide advice, positive solutions, or constructive coping. The suggestions or solutions given are per the existing SP (Implementation Strategy) for each patient observed by the researcher, including hallucinations, self-care deficits, dual drug user diagnoses, and emotional and violent behaviour.

C. Giving Appreciation

This form of appreciation is a form of appreciation given by nurses to patients. Appreciation by giving something in the form of goods is considered inappropriate, but praise given to patients when they do something positive is considered more valuable. 
With sincere appreciation, patients will feel valued and cared for. Giving appreciation is a form of reward to patients. Appreciation here is not in the form of goods but with praise every nurse who is observed to appreciate the patient. By giving appreciation, the Schizophrenia patient will feel happy. Every little thing the patient does deserves credit. Thus, patients feel cared for by nurses, so they feel that they have positive things. By giving rewards, the patient will feel more valuable. Giving appreciation is done by nurses in the work and termination phases.

\section{Conclusions and Recommendations}

The conclusion emerged in the study that 22 people (88\%) of respondents were in the Bad category in controlling negative thoughts. Meanwhile, three respondents (12\%) have an excellent ability to control negative thoughts. Most of them revealed that when they have a problem burden on their minds, they tend to tell family members about their problems. However, they did not do so for fear that their family members would be burdened with the problem.

There is also a conclusion that there are differences in depression conditions after the implementation of cognitive therapy, which shows that the decrease in depression in the elderly group who received cognitive therapy (intervention group) was higher ( $p$ value $=0.001<0.05$ ) compared to the decrease in depression in the group that did not receive the treatment adapted care.

The conclusion using the Wilcoxon test method obtained a value of 0.001 , so based on this analysis, it can be seen that $p<0.05$. The results show a significant effect of the adapted treatment process on controlling negative thoughts in Schizophrenic clients. This study also found that the inhibiting factor of therapeutic communication between nurses (from internal or external elements of the family) is the age development factor.

There are also research results that show 3 variables that support effective and efficient therapeutic communication. These are Build Trust, Troubleshooting with Constructive Coping, and Giving Appreciation.

Based on these conclusions, it is highly recommended that the family play the dominant role effectively and efficiently during the nursing process for Schizophrenic patients. The emotional closeness between the patient and his immediate family members is essential in this process. Patients are significantly affected by any form of interaction (verbal or non-verbal) given by family members. On the other hand, the patient is also very considerate of the feelings and circumstances of family members regarding the situation that is happening to him. The family members must wisely and intelligently understand, manage, and comprehensively assess every process that occurs during the treatment.

Treatment assistance from external institutions, such as hospitals or rehabilitation centres, should only be an extra in treating Schizophrenia patients. It must arise considering that each patient is expected to eventually return home and live with his family until the end of life. So do not let the most significant influence factor be outside the family institution.

Funding: Please add: This research received no external funding.

Conflicts of Interest: The authors declare no conflict of interest.

ORCID ID: Iskandarsyah Siregar: https://orcid.org/0000-0002-4529-6525

\section{References}

[1] Abdul N. (2009). Communication in Nursing Theory and Applications. Jakarta: SalembaMedika.

[2] Alwasilah, A. C. (2005). Introduction to Applied Linguistic Research. Jakarta: Pusat Bahasa.

[3] Amiruddin. (2010). Analysis of Factors Associated with the Incidence of Schizophrenia Mental Disorders in the Mental Hospital of Southeast Sulawesi Province. Thesis. Makassar: Hasanuddin University, 2010.

[4] Anugrah, A. D. (2014). Characteristics of Schizophrenic Patients Who Are Inpatient in The Special Hospital Of The Province Of South Sulawesi For The Period January-May 2013. Thesis. Makassar: Faculty of Medicine, Hasanuddin University.

[5] Azizah, N.R. (2013). Verbal Language Skills of Schizophrenic Patients: A Case Study. http://repository.unair.ac.id/27284/

[6] Iskandar. (2012). Mental Nursing Care, Self-Care Deficit. Jakarta.

[7] Kriyantono, R. (2008). Practical Techniques of Communication Research. Jakarta: Kencana.

[8] Marhaeni, D. (2009). Communication Science, Theory and Practice. Jakarta: Graha Ilmu.

[9] Nurjannah, I. (2005). Therapeutic Communication (Fundamentals of Communication for Nurses. Yogyakarta: Mocomedia.

[10] Sabrina, A., Siregar, I., \& Sosrohadi, S. (2021). Lingual Dominance and Symbolic Power in the Discourse of Using the PeduliLindungi Application as a Digital Payment Tool. International Journal of Linguistics Studies, 1(2), 52-59. https://doi.org/10.32996/ijls.2021.1.2.8

[11] Setiawan, T. M.S. (2005). Effect of Therapeutic Communication on Anxiety Levels of Preoperative Patients at Haji Adam Malik Hospital Medan. Journal of Nursing Rufaidah North Sumatra: Volume I

[12] Siregar, I. \& Siregar, R. (2021). The Relevances between Poda Na Lima Philosophy with Islamic Perspective. Budapest International Research and Critics Institute (BIRCI-Journal): Humanities and Social Sciences. https://doi.org/10.33258/birci.v4i4.3240

[13] Siregar, I. \& Salsabila. (2021). Acts of Illocutionary Speech by Ganjar Pranowo in the "One Hour Closer" Talkshow. International Journal of Arts and Humanities Studies, 1(1), 95-100. https://doi.org/10.32996/ijahs.2021.1.1.14 
[14] Siregar, I. \& Sabrina, A. (2021). Representation of Religious Values in Gurindam Twelve and Their Relevances with Modern Era. International Journal of Cultural and Religious Studies, 1(1), 50-57. https://doi.org/10.32996/ijcrs.2021.1.1.7

[15] Siregar, I. (2021). Verbal Communication of Schizophrenic Patients Due to Neurotransmitter Distortion. QALAMUNA: Jurnal Pendidikan, Sosial, Dan Agama, 13(2), 543-556.

[16] Siregar, I. (2020). Exploration and Implementation of the Cultural System as a Solution to National and State Problems. http://repository.unas.ac.id/id/eprint/811

[17] Siregar, I. (2021). Analysis of Betawi Language Interference on the Morphology of Adolescent Speech in Jakarta. Journal of Humanities and Social Sciences Studies, 3(8), 54-60. http://doi.org/10.32996/jhsss.2021.3.8.7

[18] Siregar, I. (2020). Geografi Leksikon Betawi. Jakarta: LPU Unas

[19] Siregar, I. (2021). Epistemological Challenges Against Sociolinguistics. International Journal of Linguistics Studies, 1(2), 37-42. https://doi.org/10.32996/ijls.2021.1.2.6

[20] Siregar, I. (2021). The Existence of Culture in its Relevance to the Dynamics of Globalization: Bahasa Indonesia Case Study. International Journal of Cultural and Religious Studies, 1(1), 33-38. Retrieved from https://www.al-kindipublisher.com/index.php/ijcrs/article/view/2285

[21] Siregar, l., Rahmadiyah, F., \& Siregar, A. F. Q. (2021). Linguistic Intervention in Making Fiscal and Monetary Policy. International Journal of Arts and Humanities Studies, 1(1), 50-56. https://doi.org/10.32996/ijahs.2021.1.1.8

[22] Subyakto-Nababan, S. U. (1992). Psycholinguistics: An Introduction. Jakarta: Gramedia Pustaka Utama.

[23] Suryani, Y. (2015). Deficit of Speech Pragmatics of Schizophrenic Patients at Menur Mental Hospital Surabaya: A Study of Clinical Pragmatics. Journal of Pena Indonesia, Volume 1, No.2

[24] Syafyahya, L. (1993). Verbal Language Ability in Children with Schizophrenia. Padang: University of Andalas.

[25] Tarigan, H. G. (1986). Psycholinguistics. Bandung: Angkasa Publisher.

[26] West, R. (2008). Introduction to communication theory: Theory and Application. Jakarta: Salemba Humanika. 